D..O.I: $10.3895 /$ gi.v10i1.1584

\title{
SISTEMAS DE PRODUÇÃO, O USO DE FERRAMENTAS ADEQUADAS PARA AUMENTO DE COMPETITIVIDADE NA ÁREA DE TEMPOS E MÉTODOS
}

\section{PRODUCTION SYSTEMS, THE USE OF APPROPRIATE TOOLS TO INCREASE COMPETITIVENESS IN THE AREA OF TIME AND METHODS}

\author{
Delmo Alves de Moura ${ }^{1}$; Roberto Denin Liu ${ }^{2}$ \\ ${ }^{1}$ Universidade Federal do ABC - UFABC - São Paulo - Brasil \\ delmo.moura@ufabc.edu.br \\ ${ }^{2}$ Universidade Federal do ABC - UFABC - São Paulo - Brasil \\ liudenin@gmail.com
}

\begin{abstract}
Resumo
Neste trabalho busca-se aplicar os conceitos provenientes da literatura, referente aos estudos de tempos e movimentos, no intuito de avaliar um estudo de caso para comparar sua produtividade com o uso de técnicas adequadas, fundamentadas na revisão bibliográfica sobre o tema. Buscar-seá analisar as técnicas aplicadas na área visando proporcionar mais eficiência operacional, otimização de procedimentos e realização do balanceamento da linha de produção realizando a divisão e a subdivisão de todos os movimentos necessários à execução de cada uma das tarefas, em uma série ordenada de movimentos simples e eliminando os movimentos inúteis. As teorias e técnicas provenientes do estudo de tempos e movimentos, processos gerais de solução de problemas, estudo do trabalho, desenvolvimento do método, ergonomia e estudo de micromovimentos são elementos essênciais para análise de produtividade industrial. Estes estudos racionalizam o trabalho podendo eliminar grandes problemas que podem ser encontrados em qualquer empresa onde há produção em série em larga escala e com alto volume de colaboradores distribuídos ao longo do processo produtivo.
\end{abstract}

Palavras-chave: tempos; métodos; competitividade.

\section{Introdução}

Um sistema de produção é composto de um grande número de etapas que, individual ou coletivamente, interferem na produtividade de todo o sistema. A etapa de fabricação tem uma importância particular. Segundo estudos perde-se muito tempo com movimentação e filas de espera nas empresas e pouquíssimo tempo é gasto com a transformação do produto em sua manufatura. Gasta-se, também, um tempo considerável com a preparação de máquinas - set up (RIBEIRO, MEGUELATI, 2002).

O instrumento básico para se racionalizar o trabalho é o estudo dos tempos e movimentos (motions time study). O Trabalho é executado melhor e mais economicamente por meio da análise 
dos métodos das operações, isto é, da divisão e subdivisão de todos os movimentos necessários à execução de cada operação de uma tarefa. Os movimentos inúteis devem ser eliminados enquanto que os movimentos úteis devem ser simplificados, racionalizados ou fundidos com outros movimentos para proporcionar economia de tempo e de esforço do colaborador. A essa análise do trabalho define-se o estudo dos tempos e movimentos, ou seja, a determinação do tempo médio que um funcionário comum leva para a executar uma tarefa.

Com isso padroniza-se o método de trabalho e o tempo destinado à sua execução. O método é a maneira de se fazer algo para obter um determinado resultado. O estudo dos tempos e movimentos permite a racionalização do método de trabalho do colaborador e a fixação dos tempospadrão para execução das tarefas. Outras vantagens adicionais com este estudo são:

- Eliminação do desperdício de esforço humano e dos movimentos inúteis;

- Racionalização da seleção e adaptação dos operários à tarefa;

- Facilidade no treinamento dos operários e melhoria da eficiência e rendimento da produção para especialização das atividades;

- Distribuição uniforme do trabalho para que não haja períodos de falta ou excesso de trabalho;

- Definição de métodos e estabelecimento de normas para a execução do trabalho;

- Estabelecimento de uma base uniforme para salários equitativos e prêmios de produção.

\section{A importância da área de tempos e métodos}

Uma das decorrências do estudo de tempos e movimentos é a divisão do trabalho e a especialização do colaborador a fim de elevar sua produtividade.

O estudo de movimentos e de tempos é o estudo sistemático dos sistemas de trabalho coma os seguintes objetivos: (a) desenvolver o sistema e o método preferido, usualmente aquele de menor custo; (b) padronizar- esse sistema e método; (c) determinar o tempo gasto por uma pessoa qualificada e devidamente treinada, trabalhando num ritmo norma, para executar uma tarefa ou operação específica; e (d) orientar o treinamento do trabalhador no método preferido (BARNES, 1977).

Uma ferramenta no campo da engenharia de tempos, métodos e processos, quando deseja-se determinar a eficiência no trabalho, através da determinação de padrões para os programas de produção e redução de custos industriais é o estudo de tempos e movimentos, ela permite aumento dos rendimentos e da eficiência operacional, proporciona melhor postura ergonômica, otimização de procedimentos e realização do balanceamento da linha de produção. Utilizando-se esta ferramenta no início da implantação de um projeto, determina-se a capacidade de produção de uma 
máquina ou linha de produção, o espaço necessário e a quantidade de pessoas que devem ser contratadas além de eliminar o desperdício reduzindo, assim, os custos da produção.

Taylor foi o pioneiro no estudo de tempo, a principal motivação é determinar o tempo padrão. Já o estudo de movimentos foi introduzido pelo casal Gilbreth com o objetivo de melhorar métodos de trabalho, este estudo objetiva identificar os elementos componentes dos movimentos do operador, melhoria dos métodos e posterior fixação do tempo padrão (TUJI JÚNIOR, et al, 2002). Hoje a preocupação principal é a definição de sistemas e métodos de trabalho, o objetivo é determinar o método ideal ou aquele que mais se aproximaria do ideal para ser executado na prática.

O estudo de movimentos e de tempos é o estudo ordenado dos sistemas de trabalho que possui os objetivos de desenvolver sistemas de método preferido, padronizar o sistema, determinar o tempo gasto por uma pessoa qualificada que esteja trabalhando num ritmo normal para executar a operação e, por fim, orientar o treinamento do trabalhador no método preferido (BARNES, 1977; FALZON, 2007; IIDA, 2005).

O estudo do trabalho possui dois grupos, o estudo de métodos que se concentra na determinação dos métodos e atividades que devem ser incluídos nos trabalhos e o estudo de medidas do trabalho que se concentra na medição do tempo que deve despender a execução de trabalhos. O estudo do método tem por objetivo registrar de forma sistêmica e examinar criticamente os métodos existentes e propostos para realizar o trabalho, buscando mecanismos de aperfeiçoar ou até mesmo aplicar uma nova metodologia a fim de realizar uma tarefa buscando otimizá-la e reduzir os custos. O estudo do Tempo é uma técnica para registrar os tempos e o ritmo e trabalho para os elementos de uma tarefa especializada e para analisar os dados de forma a obter o tempo a fim de realizar o trabalho com um nível definido de desempenho (SLACK, 2002; FLUENTES, DIAZ, 2012).

Ergonomia: O objetivo da ergonomia é o estudo da adaptação das tarefas e do ambiente de trabalho ás características sensoriais, perceptivas, mentais e físicas das pessoas. Essa adaptação leva a consecução de melhores projetos de equipamentos, de sistemas homem máquina, de produtos de consumo, de métodos e ambientes de trabalho (ERNEST, 1957).

O objeto em estudo é o ser humano, suas habilidades, capacidades e limitações. Com esses conhecimentos, pode-se dizer quais são as ferramentas, materiais e métodos de trabalho que melhor se lhe adaptam.

Estudo de micromovimentos: Este estudo permite obter uma técnica para registrar e medir o tempo gasto em uma atividade. Consiste em se filmar a operação, de modo que um relógio seja incluído na cena ou, então, usando-se máquinas de filmar que opere em velocidade constante e 
conhecida. Assim o filme torna-se um registro permanente do método seguido na execução e do tempo gasto, podendo ser reavaliado em qualquer instante. As principais aplicações do estudo de micromovimentos são:

- procurar o melhor método de se executar uma tarefa e;

- treinar pessoas para entenderem o verdadeiro sentido do estudo de micromovimentos e, quando o treinamento alcança bons resultados, para torná-los mais eficientes na aplicação dos princípios de economia dos movimentos.

Estudo do tempo: Este possui o objetivo de determinar o tempo gasto por uma pessoa qualificada, trabalhando em um ritmo normal e executando uma certa tarefa.O estudo de tempo é usado para medir o trabalho, o seu resultado é o tempo em minutos que uma pessoa adaptada ao trabalho demandaria para completar a tarefa. Isto permite planejar o trabalho, determinar os custospadrão e estimar o custo de um produto antes da sua fabricação, determina a eficiência de máquina, o número de máquinas que uma pessoa poderia operar, o número de operários necessários numa linha de produção e determinar o tempo-padrão a serem usados como base para o pagamento aos funcionários (STERNBERG, et al, 2013).

\section{Visão geral do estudo de movimentos e de tempos}

No planejamento dos processos de fabricação de algo, leva-se em conta todas as operações feitas por todas as pessoas e nesse planejamento emprega-se o sistema geral de problema-solução, este é definido da seguinte maneira: definição do problema, análise do problema, pesquisa de soluções possíveis, avaliação das alternativas e recomendação para a ação.

Após o desenvolvimento do melhor método de executar uma operação, deve-se padronizálo. Como as tarefas são divididas em trabalhos, deve-se descrevê-los em detalhes especificando a sua execução.

$\mathrm{O}$ estudo de movimentos e de tempos determina quanto tempo um operário qualificado gastaria para executar uma tarefa, este tempo é chamado de tempo padrão. Uma vez que este é determinado, ele é utilizado para planejamento da produção e estimar o custo da mão de obra. A forma mais comum de se medir o trabalho humano é a cronometragem, cada elemento da operação é cronometrado, estes elementos recebem um tempo representativo, em cima delas adiciona-se tempos elementares e assim obtém-se o tempo total para executar a operação. Um observador, ao avaliar a velocidade do operador durante a cronometragem, ele ajusta o tempo utilizado pelo operador qualificado para que ele venha a executar sem dificuldades o trabalho no tempo especificado, este tempo ajustado é chamado de tempo normal e nela adiciona-se ainda as 
tolerâncias para necessidades pessoais como as fadigas obtendo, assim, o tempo padrão (FURLAN, et al, 2011).

Um exame cuidadoso deve ser feito para se verificar até que ponto cada solução atende ao critério e às especificações originais. Deve-se fazer uma avaliação quantitativa e considerar todos os fatores para julgamento a fim de chegar ao método preferido. Mesmo que algumas soluções possam atender as especificações, é improvável que, algumas soluções possam ser preferidas caso algumas restrições seja mudadas. Neste passo deve-se levar em conta as dificuldades futuras tais como o tempo e o custo necessário para reparar algum equipamento, o desgaste das máquinas que poderão interferir na qualidade dos equipamentos a demanda futura, entre outros. A avaliação também deve girar-se em torno do capital disponível para investimentos em dada método proposto, neste aspecto, procura-se conhecer o custo inicial, o custo operacional anual, o tempo de vida do equipamento e o valor de reposição. Normalmente, a maior preocupação é determinar o método de menor custo de mão de obra (CHAYET, 2011).

A capacidade produtiva é a quantidade máxima de produtos ou serviços possíveis de serem feitas em um determinado tempo. A fim de realizar o aumento da capacidade de uma unidade, devese alterar os fatores que determinam essa capacidade. Alguns deles não possuem grandes dificuldades, porém há os que dependem de mudanças mais custosas ou que tomariam muito tempo (MOREIRA, 2002; JIMÉNEZ-JIMÉNEZ, COSTA, 2009).

Ao se produzir um novo produto este deve ser projetado, deve-se especificar quais são os materiais necessários para produzi-lo, verificar quais deveriam ser os equipamentos e as máquinas adequadas e escolher a metodologia. É comum dividir um processo é várias operações simples, porém em alguns casos a divisão de trabalho torna-se exagerada. Subdividir um processo em muitas operações causa um excessivo manuseio de materiais, ferramentas e equipamentos provocando dificuldades no balanceamento de uma linha de produção, gargalos e esperas. Dessa forma, às vezes é possível tornar-se o trabalho mais simples pela combinação de duas ou mais operações ou alterações no método, que permitam a combinação de operações (GUPTA, BOYD, 2011; HASLE, et al, 2012).

\section{Ferramentas para a melhoria dos métodos}

Deve-se fazer um estudo global em do processo produtivo seguida de uma análise de cada um dos passos que compõem o processo de fabricação.

- Gráfico do fluxo do processo: É uma técnica para se registrar um processo de maneira compacta, a fim de tornar possível sua melhor compreensão e posterior melhoria. $\mathrm{O}$ gráfico representa os diversos passos ou eventos que ocorrem durante a execução de uma tarefa específica, ou durante uma série de ações. O diagrama, usualmente, tem início com a entrada da matéria-prima 
na fábrica e a segue em cada um dos seus passos, tais como transportes e armazenamentos, inspeções, usinagens, montagens, até que ela se torne ou um produto acabado, ou parte de um subconjunto. Assim, há uma facilidade de visualizar as operações e fazer melhorias eliminando, combinando, sequenciando ou rearranjando as operações (BARNES, 1977; DAILY et al, 2012).

Uma operação ocorre quando um objeto é modificado intencionalmente numa ou mais das suas características. Um transporte ocorre quando um objeto é deslocado de um lugar para outro, exceto quando o movimento é parte integral de uma operação ou inspeção. Uma inspeção ocorre quando um objeto é examinado para identificação ou comparado com um padrão de quantidade ou qualidade. Uma espera ocorre quando a execução da próxima ação planejada não é efetuada. Um armazenamento ocorre quando um objeto é mantido sob controle e a sua retirada requer um autorização (BARNES, 1977; NARASIMHAN, et al, 2012).

\subsection{Ergonomia}

A análise ergonômica busca alcançar resultados positivos em duas principais esferas: Uma centrada na organização e no seu desempenho (produtividade, eficiência, qualidade, etc.), e outra centrada nas pessoas (segurança, saúde, conforto, facilidade de uso, bem estar, etc). Certas vezes essas esferas entram em tensão entre si. Dessa maneira, dentro de uma organização, é necessário buscar o melhor trade-off entre essas duas esferas. A ergonomia não deve colocar a produtividade e a eficiência como objetivos principais, caso contrário , poderia causar sofrimento e mal estar no trabalhador durante a execução de suas atividades (BOLIS, 2011).

Ao desenvolver-se uma ação ergonômica, deve-se buscar elementos que permitam transformar o trabalho e produzir conhecimentos. Nesta perspectiva a ergonomia foi se desenvolvendo, adotando como referência a noção de variabilidade, a distinção entre tarefas e atividade, e a regulação das ações associada ao reconhecimento da competência dos trabalhadores (ABRAHÃO, et al, 2009).

É importante diferenciar o conceito de tarefa e de atividade: “A tarefa é o que se deve fazer, o que é prescrito pela organização. A atividade é o que é feito, o que o sujeito mobiliza para efetuar a tarefa" (FALZON, 2007 ). Com estes conceitos, a tarefa é o trabalho ordenado pela empresa, o qual define as atividades, e assim o trabalho real (BOLIS, 2011). Para que se desenvolva uma boa análise ergonômica, é necessário que haja colaboração entre os trabalhadores e quem analisa. Através da análise do trabalho real, é possível identificar o modo estratégico que os trabalhadores utilizam e dessa forma, pode-se identificar quais seriam as dificuldades a fim de tomar as atitudes eficazes para melhorar ou amenizar as condições de trabalho (DANIELLOU, 2004).

Os conhecimentos que o projetista de máquinas, equipamento, método de trabalho e ambiente de trabalho são as funções do ser humano, dimensão de seu corpo, suas limitações e as 
condições nas quais age mais eficientemente. Desse modo, pode-se projetar qualquer processo verificando as atividades que devem ser realizadas pelo homem e quais pela máquina. As capacidades que os seres humanos são melhores que as máquinas são: percepção de pequenas quantidades de luz ou som, organizar padrões de luz ou som, improvisar e utilizar procedimentos flexíveis, acumular e guardar grande quantidade de informações por longos períodos e relembrar os fatos importantes no tempo apropriado, raciocinar indutivamente, exercer julgamento, desenvolver conceitos e criar métodos. As máquinas superam os seres humanos nas seguintes capacidades: Reagir rapidamente a sinais de controle, aplicar grandes forças suavemente e com precisão, realizar tarefas repetitivas, guardar informações por breves períodos e depois cancelá-las completamente, realizar cálculos rapidamente e diversas funções diferentes simultaneamente (ERNEST, 1957).

O método de trabalho deve ser projetado de modo a permitir que o operador realize a tarefa no menor tempo possível e com maior facilidade e satisfação. O número de membros do corpo envolvidos e o número de movimentos executados deverão ser os menores possíveis bem como o comprimento dos movimentos deverá ser menor possível. Também deve-se levar em conta que o trabalho deverá ser projetado de forma a diminuir o desgaste de energia e menor tensão fisiológica possível .

\section{Metodologia}

Este trabalho é fundamentado na proposta metodológica descrita como pesquisa de natureza básica, com abordagem qualitativa, com objetivo descritivo e procedimentos técnicos baseados na revisão bibliográfica, com um estudo.

Utilizou-se um estudo comparativo e específico de dois casos empíricos a fim de aplicar os conceitos e as ferramentas inerentes ao estudo de tempo e movimentos. Os casos empíricos são duas indústrias que fabricam um relógio compostos por dezoito peças. A partir de uma demanda foi estabelecido um método na linha de produção para cada indústria. Com isto, para que as empresas venham a atender a demanda com a metodologia estabelecida, foi realizado estudos nos métodos de trabalho voltados para os micromovimentos na linha de produção utilizando as tabelas de MTM, podendo assim determinar quantos postos de trabalho serão necessários, divisão das operações em elementos, determinação do tempo padrão, balancear a linha de produção para alcançar a eficiência máxima e por fim determinar o número de colaboradores nos dois métodos de trabalho estabelecido e assim, concluir qual delas conseguiria reduzir ao máximo o custo unitário da produção do relógio.

\section{Descrição dos estudos de movimentos e tempos - MTM}

A Tabela 1 apresenta as informações necessárias para início das análises dos dois casos em estudo. 


\begin{tabular}{cccccc}
$\begin{array}{c}\text { Jornada de } \\
\text { trabalho diário(h) }\end{array}$ & $\begin{array}{c}\text { Demanda } \\
\text { por mês }\end{array}$ & $\begin{array}{c}\text { Tabela 1- Informações para o estudo } \\
\text { Tempo } \\
\text { total(s) }\end{array}$ & $\begin{array}{c}\text { Tempo de produção } \\
\text { unitário(s) }\end{array}$ & $\begin{array}{c}\text { Fator de } \\
\text { tolerância(\%) }\end{array}$ & $\begin{array}{c}\text { Fator de } \\
\text { ritmo (\%) }\end{array}$ \\
\hline 8 & 93500 & 864000 & 9,24 & $1 \%$ & $110 \%$ \\
\hline
\end{tabular}

Fonte: Pesquisa de campo (2012)

O tempo total é o tempo disponível de um operador para um mês, ele foi determinado a partir da jornada de um trabalhador e o tempo de produção unitário. Assim, para que a empresa consiga atender a demanda, deve-se desenvolver metodologias de produção para produzir um produto dentro do tempo estabelecido.

Para a empresa 1, inicialmente foi feito um planejamento realizou-se o projeto do processo que consistiu em determinar sistema de produção considerando todas as operações necessários, as sequências das tarefas, as tolerâncias e os equipamentos. Também foi realizado o projeto de método de trabalho e a determinação do tempo padrão.

A método desenvolvido a partir das ferramentas estudadas para cada posto de trabalho está apresentado nas Tabelas 2 até 13. As tarefas foram subdivididas de modo a atender o tempo estabelecido, assim cada posto de trabalho não deveria ultrapassar 9,24s de operação, caso contrário, a empresa não conseguiria atender a demanda. $\mathrm{O}$ tempo relacionado a cada micromovimento, foram baseados nas tabelas de Method Time Measurement (BARNES, 1977).

\begin{tabular}{|c|c|c|c|c|c|}
\hline \multicolumn{2}{|l|}{ Mão esquerda } & \multicolumn{2}{|l|}{ Mão direita } & \multirow[b]{2}{*}{$\begin{array}{l}\text { Tempo Maior } \\
\text { (TMU) }\end{array}$} & \multirow[b]{2}{*}{$\begin{array}{c}\text { Tempo } \\
(\mathrm{s})\end{array}$} \\
\hline Micromovimento & $\begin{array}{l}\text { Tempo } \\
\text { (TMU) }\end{array}$ & Micromovimento & $\begin{array}{l}\text { Tempo } \\
\text { (TMU) }\end{array}$ & & \\
\hline Transporte Vazio & 5,8 & Transporte Vazio & 5,8 & 5,8 & 0,21 \\
\hline Selecionar Lente & 21 & Selecionar Carcaça & 21 & 21 & 0,76 \\
\hline Agarrar & 2 & Agarrar & 2 & 2 & 0,07 \\
\hline Segurar & 2 & Segurar & 2 & 2 & 0,07 \\
\hline Transporte Carregado & 10,3 & Transporte Carregado & 10,3 & 10,3 & 0,37 \\
\hline Pré-posicionar & 5,8 & Segurar & 5,8 & 5,8 & 0,21 \\
\hline Posicionar & 14,7 & Segurar & 14,7 & 14,7 & 0,53 \\
\hline Montar & 2 & Segurar & 2 & 2 & 0,07 \\
\hline Soltar & 2 & Segurar & 2 & 2 & 0,07 \\
\hline Demora inevitável & 10,3 & Transporte Carregado & 10,3 & 10,3 & 0,37 \\
\hline Demora inevitável & 2 & $\begin{array}{c}\text { Soltar na mesa lente + carcaça } \\
\text { montados }\end{array}$ & 2 & 2 & 0,07 \\
\hline Transporte Vazio & 5,8 & Transporte Vazio & 5,8 & 5,8 & 0,21 \\
\hline Selecionar encaixe da placa & 21 & Selecionar placa & 21 & 21 & 0,76 \\
\hline Agarrar & 2 & Agarrar & 2 & 2 & 0,07 \\
\hline Segurar & 2 & Segurar & 2 & 2 & 0,07 \\
\hline Transporte Carregado & 10,3 & Transporte Carregado & 10,3 & 10,3 & 0,37 \\
\hline Pré-posicionar & 5,8 & Segurar & 5,8 & 5,8 & 0,21 \\
\hline Posicionar & 14,7 & demora inevitável & 14,7 & 14,7 & 0,53 \\
\hline Transporte Carregado & 10,3 & Transporte Carregado & 10,3 & 10,3 & 0,37 \\
\hline Posicionar na mesa & 14,7 & Posicionar na mesa & 14,7 & 14,7 & 0,53 \\
\hline \multirow[t]{2}{*}{$\begin{array}{c}\text { Soltar na mesa placa + } \\
\text { encaixe da placa }\end{array}$} & 2 & Soltar & 2 & 2 & 0,07 \\
\hline & & & & Tempo total (s) & 5,99 \\
\hline
\end{tabular}

Fonte: Pesquisa de campo (2012) 
Tabela 3 - Posto 2

\begin{tabular}{|c|c|c|c|c|c|}
\hline \multicolumn{2}{|c|}{ Mão esquerda } & \multicolumn{2}{|c|}{ Mão direita } & \multirow[b]{2}{*}{$\begin{array}{c}\text { Tempo Maior } \\
\text { (TMU) }\end{array}$} & \multirow[b]{2}{*}{ Tempo (s) } \\
\hline Micromovimento & $\begin{array}{l}\text { Tempo } \\
\text { (TMU) }\end{array}$ & Micromovimento & $\begin{array}{l}\text { Tempo } \\
\text { (TMU) }\end{array}$ & & \\
\hline Transporte Vazio & 5,8 & Transporte Vazio & 5,8 & 5,8 & 0,21 \\
\hline Selecionar parafuso & 21 & $\begin{array}{c}\text { Selecionar } \\
\text { parafusadeira }\end{array}$ & 21 & 21 & 0,76 \\
\hline Agarrar & 2 & Agarrar & 2 & 2 & 0,07 \\
\hline Segurar & 2 & Segurar & 2 & 2 & 0,07 \\
\hline $\begin{array}{l}\text { Transporte } \\
\text { Carregado }\end{array}$ & 10,3 & $\begin{array}{l}\text { Transporte } \\
\text { Carregado }\end{array}$ & 10,3 & 10,3 & 0,37 \\
\hline Pré-posicionar & 5,8 & Pré-posicionar & 5,8 & 5,8 & 0,21 \\
\hline Posicionar & 14,7 & Posicionar & 14,7 & 14,7 & 0,53 \\
\hline Segurar & 41 & Parafusar & 41 & 41 & 1,48 \\
\hline Soltar & 2 & $\begin{array}{l}\text { Transporte } \\
\text { Carregado }\end{array}$ & 10,3 & 10,3 & 0,37 \\
\hline Demora inevitável & 14,7 & Posicionar & 14,7 & 14,7 & 0,53 \\
\hline Demora inevitável & 2 & soltar & 2 & 2 & 0,07 \\
\hline
\end{tabular}

Fonte: Pesquisa de campo (2012)

Tabela 4 - Posto 3

\begin{tabular}{|c|c|c|c|c|c|}
\hline \multicolumn{2}{|c|}{ Mão esquerda } & \multicolumn{2}{|c|}{ Mão direita } & \multirow[b]{2}{*}{$\begin{array}{c}\text { Tempo Maior } \\
\text { (TMU) }\end{array}$} & \multirow[b]{2}{*}{ Tempo (s) } \\
\hline Micromovimento & $\begin{array}{l}\text { Tempo } \\
\text { (TMU) }\end{array}$ & Micromovimento & $\begin{array}{l}\text { Tempo } \\
\text { (TMU) }\end{array}$ & & \\
\hline Transporte Vazio & 5,8 & Transporte Vazio & 5,8 & 5,8 & 0,21 \\
\hline Selecionar parafuso & 21 & $\begin{array}{c}\text { Selecionar } \\
\text { parafusadeira }\end{array}$ & 21 & 21 & 0,76 \\
\hline Agarrar & 2 & Agarrar & 2 & 2 & 0,07 \\
\hline Segurar & 2 & Segurar & 2 & 2 & 0,07 \\
\hline $\begin{array}{l}\text { Transporte } \\
\text { Carregado }\end{array}$ & 10,3 & $\begin{array}{l}\text { Transporte } \\
\text { Carregado }\end{array}$ & 10,3 & 10,3 & 0,37 \\
\hline Pré-posicionar & 5,8 & Pré-posicionar & 5,8 & 5,8 & 0,21 \\
\hline Posicionar & 14,7 & Posicionar & 14,7 & 14,7 & 0,53 \\
\hline Segurar & 41 & Parafusar & 41 & 41 & 1,48 \\
\hline Soltar & 2 & $\begin{array}{l}\text { Transporte } \\
\text { Carregado }\end{array}$ & 10,3 & 10,3 & 0,37 \\
\hline Demora inevitável & 14,7 & Posicionar & 14,7 & 14,7 & 0,53 \\
\hline Demora inevitável & 2 & soltar & 2 & 2 & 0,07 \\
\hline & & & & Tempo total (s) & 4,67 \\
\hline
\end{tabular}

Fonte: Pesquisa de campo (2012)

Tabela 5 - Posto 4

\begin{tabular}{|c|c|c|c|c|c|}
\hline \multicolumn{2}{|c|}{ Mão esquerda } & \multicolumn{2}{|c|}{ Mão direita } & \multirow[b]{2}{*}{$\begin{array}{l}\text { Tempo Maior } \\
\text { (TMU) }\end{array}$} & \multirow[b]{2}{*}{ Tempo (s) } \\
\hline Micromovimento & $\begin{array}{l}\text { Tempo } \\
\text { (TMU) }\end{array}$ & Micromovimento & $\begin{array}{l}\text { Tempo } \\
\text { (TMU) }\end{array}$ & & \\
\hline Transporte Vazio & 5,8 & Transporte Vazio & 5,8 & 5,8 & 0,21 \\
\hline Selecionar parafuso & 21 & $\begin{array}{c}\text { Selecionar } \\
\text { parafusadeira }\end{array}$ & 21 & 21 & 0,76 \\
\hline Agarrar & 2 & Agarrar & 2 & 2 & 0,07 \\
\hline Segurar & 2 & Segurar & 2 & 2 & 0,07 \\
\hline $\begin{array}{l}\text { Transporte } \\
\text { Carregado }\end{array}$ & 10,3 & $\begin{array}{l}\text { Transporte } \\
\text { Carregado }\end{array}$ & 10,3 & 10,3 & 0,37 \\
\hline Pré-posicionar & 5,8 & Pré-posicionar & 5,8 & 5,8 & 0,21 \\
\hline Posicionar & 14,7 & Posicionar & 14,7 & 14,7 & 0,53 \\
\hline Segurar & 41 & Parafusar & 41 & 41 & 1,48 \\
\hline Soltar & 2 & $\begin{array}{l}\text { Transporte } \\
\text { Carregado }\end{array}$ & 10,3 & 10,3 & 0,37 \\
\hline Demora inevitável & 14,7 & Posicionar & 14,7 & 14,7 & 0,53 \\
\hline Demora inevitável & 2 & soltar & 2 & 2 & 0,07 \\
\hline & & & & Tempo total (s) & 4,67 \\
\hline
\end{tabular}

Fonte: Pesquisa de campo (2012) 
Tabela 6 - Posto 5

\begin{tabular}{|c|c|c|c|c|c|}
\hline \multicolumn{2}{|c|}{ Mão esquerda } & \multicolumn{2}{|c|}{ Mão direita } & \multirow[b]{2}{*}{$\begin{array}{c}\text { Tempo Maior } \\
\text { (TMU) }\end{array}$} & \multirow[b]{2}{*}{ Tempo (s) } \\
\hline Micromovimento & $\begin{array}{l}\text { Tempo } \\
\text { (TMU) }\end{array}$ & Micromovimento & $\begin{array}{l}\text { Tempo } \\
\text { (TMU) }\end{array}$ & & \\
\hline Transporte Vazio & 5,8 & Transporte Vazio & 5,8 & 5,8 & 0,21 \\
\hline Selecionar parafuso & 21 & $\begin{array}{c}\text { Selecionar } \\
\text { parafusadeira }\end{array}$ & 21 & 21 & 0,76 \\
\hline Agarrar & 2 & Agarrar & 2 & 2 & 0,07 \\
\hline Segurar & 2 & Segurar & 2 & 2 & 0,07 \\
\hline $\begin{array}{l}\text { Transporte } \\
\text { Carregado }\end{array}$ & 10,3 & Transporte Carregado & 10,3 & 10,3 & 0,37 \\
\hline Pré-posicionar & 5,8 & Pré-posicionar & 5,8 & 5,8 & 0,21 \\
\hline Posicionar & 14,7 & Posicionar & 14,7 & 14,7 & 0,53 \\
\hline Segurar & 41 & Parafusar & 41 & 41 & 1,48 \\
\hline Soltar & 2 & Transporte Carregado & 10,3 & 10,3 & 0,37 \\
\hline Demora inevitável & 14,7 & Posicionar & 14,7 & 14,7 & 0,53 \\
\hline Demora inevitável & 2 & soltar & 2 & 2 & 0,07 \\
\hline Demora inevitável & 5,8 & Transporte Vazio & 5,8 & 5,8 & 0,21 \\
\hline Demora inevitável & 21 & $\begin{array}{c}\text { Selecionar placa }+ \\
\text { encaixe }\end{array}$ & 21 & 21 & 0,76 \\
\hline Demora inevitável & 2 & Agarrar segurar & 2 & 2 & 0,07 \\
\hline Demora inevitável & 10,3 & Transporte Carregado & 10,3 & 10,3 & 0,37 \\
\hline Demora inevitável & 14,7 & Posicionar & 14,7 & 14,7 & 0,53 \\
\hline Demora inevitável & 2 & Soltar & 2 & 2 & 0,07 \\
\hline & & & & Tempo total (s) & 6,67 \\
\hline
\end{tabular}

Fonte: Pesquisa de campo (2012)

Tabela 7 - Posto 6

\begin{tabular}{|c|c|c|c|c|c|}
\hline \multicolumn{2}{|c|}{ Mão esquerda } & \multicolumn{2}{|c|}{ Mão direita } & \multirow[b]{2}{*}{$\begin{array}{c}\text { Tempo Maior } \\
\text { (TMU) }\end{array}$} & \multirow[b]{2}{*}{ Tempo (s) } \\
\hline Micromovimento & $\begin{array}{l}\text { Tempo } \\
\text { (TMU) }\end{array}$ & Micromovimento & $\begin{array}{l}\text { Tempo } \\
\text { (TMU) }\end{array}$ & & \\
\hline $\begin{array}{c}\text { Segurar placa }+ \\
\text { encaixe }\end{array}$ & 5,8 & Transporte Vazio & 5,8 & 5,8 & 0,21 \\
\hline Segurar & 21 & Selecionar peso 1 & 21 & 21 & 0,76 \\
\hline Segurar & 2 & Agarrar & 2 & 2 & 0,07 \\
\hline Segurar & 2 & Segurar & 2 & 2 & 0,07 \\
\hline Segurar & 10,3 & $\begin{array}{l}\text { Transporte } \\
\text { Carregado }\end{array}$ & 10,3 & 10,3 & 0,37 \\
\hline Segurar & 5,8 & Pré-posicionar & 5,8 & 5,8 & 0,21 \\
\hline Segurar & 14,7 & Posicionar & 14,7 & 14,7 & 0,53 \\
\hline Segurar & 2 & Soltar & 2 & 2 & 0,07 \\
\hline Segurar & 5,8 & Transporte Vazio & 5,8 & 5,8 & 0,21 \\
\hline Segurar & 21 & Selecionar peso 1 & 21 & 21 & 0,76 \\
\hline Segurar & 2 & Agarrar & 2 & 2 & 0,07 \\
\hline Segurar & 2 & Segurar & 2 & 2 & 0,07 \\
\hline Segurar & 10,3 & $\begin{array}{l}\text { Transporte } \\
\text { Carregado }\end{array}$ & 10,3 & 10,3 & 0,37 \\
\hline Segurar & 5,8 & Pré-posicionar & 5,8 & 5,8 & 0,21 \\
\hline Segurar & 14,7 & Posicionar & 14,7 & 14,7 & 0,53 \\
\hline Soltar & 2 & Soltar & 2 & 2 & 0,07 \\
\hline & & & & Tempo total (s) & 4,58 \\
\hline
\end{tabular}

Fonte: Pesquisa de campo (2012)

Tabela 8 - Posto 7

\begin{tabular}{cc|cc|cc}
\hline \multicolumn{2}{c|}{ Mão esquerda } & \multicolumn{2}{c|}{ Mão direita } & & \\
\hline Micromovimento & $\begin{array}{c}\text { Tempo } \\
\text { (TMU) }\end{array}$ & Micromovimento & $\begin{array}{c}\text { Tempo } \\
\text { (TMU) }\end{array}$ & $\begin{array}{c}\text { Tempo Maior } \\
\text { (TMU) }\end{array}$ & Tempo (s) \\
\hline Transporte Vazio & 5,8 & Transporte Vazio & 5,8 & 5,8 & 0,21 \\
Selecionar parafuso & 21 & $\begin{array}{c}\text { Selecionar } \\
\text { parafusadeira }\end{array}$ & 21 & 21 & 0,76 \\
Agarrar & 2 & Agarrar & 2 & 2 & 0,07 \\
Segurar & 2 & Segurar & 2 & 2 & 0,07
\end{tabular}




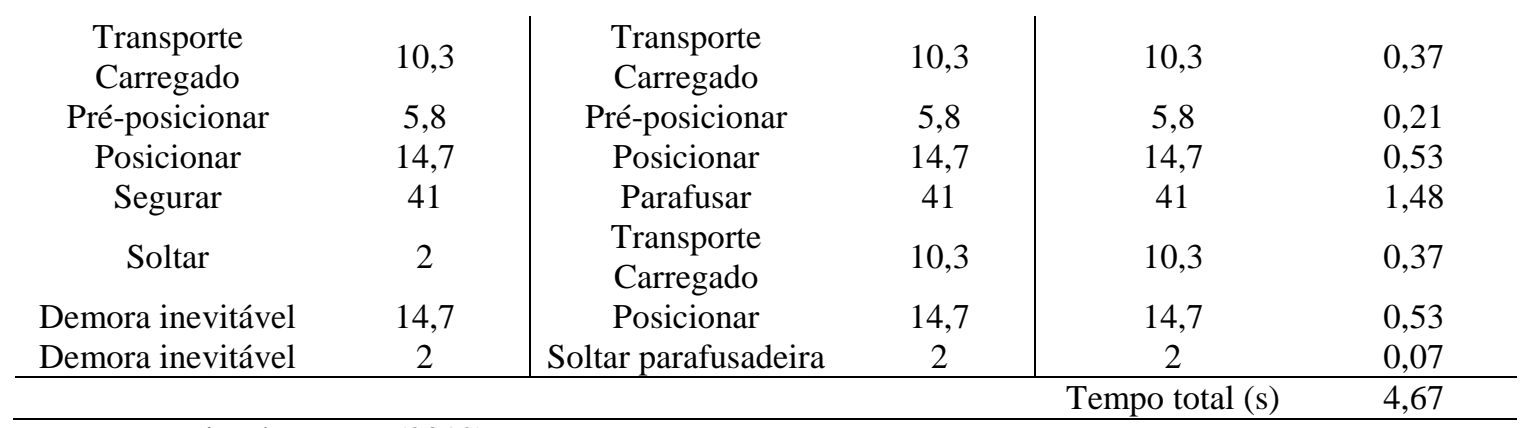

Tabela 9 - Posto 8

\begin{tabular}{|c|c|c|c|c|c|}
\hline \multicolumn{2}{|c|}{ Mão esquerda } & \multicolumn{2}{|l|}{ Mão direita } & \multirow[b]{2}{*}{$\begin{array}{l}\text { Tempo Maior } \\
\text { (TMU) }\end{array}$} & \multirow[b]{2}{*}{ Tempo (s) } \\
\hline Micromovimento & $\begin{array}{l}\text { Tempo } \\
\text { (TMU) }\end{array}$ & Micromovimento & $\begin{array}{l}\text { Tempo } \\
\text { (TMU) }\end{array}$ & & \\
\hline Transporte Vazio & 5,8 & Demora inevitável & 5,8 & 5,8 & 0,21 \\
\hline $\begin{array}{l}\text { Selecionar carcaça } \\
+ \text { lente }\end{array}$ & 21 & Demora inevitável & 21 & 21 & 0,76 \\
\hline Agarrar & 2 & Demora inevitável & 2 & 2 & 0,07 \\
\hline Segurar & 2 & Demora inevitável & 2 & 2 & 0,07 \\
\hline $\begin{array}{l}\text { Transporte } \\
\text { Carregado }\end{array}$ & 10,3 & Demora inevitável & 10,3 & 10,3 & 0,37 \\
\hline Segurar & 5,8 & Transporte Vazio & 5,8 & 5,8 & 0,21 \\
\hline Segurar & 21 & $\begin{array}{l}\text { Selecionar placa }+ \text { o conjunto } \\
\text { montado }\end{array}$ & 21 & 21 & 0,76 \\
\hline Segurar & 2 & Agarrar & 2 & 2 & 0,07 \\
\hline Segurar & 2 & Segurar & 2 & 2 & 0,07 \\
\hline Segurar & 10,3 & Transporte Carregado & 10,3 & 10,3 & 0,37 \\
\hline Segurar & 14,7 & Posicionar & 14,7 & 14,7 & 0,53 \\
\hline Segurar & 2 & Montar & 2 & 2 & 0,07 \\
\hline Segurar & 5,8 & Transporte Vazio & 5,8 & 5,8 & 0,21 \\
\hline Segurar & 21 & Selecionar Encaixe da carcaça & 21 & 21 & 0,76 \\
\hline Segurar & 2 & Agarrar & 2 & 2 & 0,07 \\
\hline Segurar & 2 & Segurar & 2 & 2 & 0,07 \\
\hline Segurar & 10,3 & Transporte Carregado & 10,3 & 10,3 & 0,37 \\
\hline Segurar & 14,7 & Posicionar & 14,7 & 14,7 & 0,53 \\
\hline Segurar & 2 & Montar & 2 & 2 & 0,07 \\
\hline Segurar & 2 & Soltar & 2 & 2 & 0,07 \\
\hline Segurar & 5,8 & Transporte Vazio & 5,8 & 5,8 & 0,21 \\
\hline Segurar & 21 & Selecionar Suporte inferior & 21 & 21 & 0,76 \\
\hline Segurar & 2 & Agarrar & 2 & 2 & 0,07 \\
\hline Segurar & 2 & Segurar & 2 & 2 & 0,07 \\
\hline Segurar & 10,3 & Transporte Carregado & 10,3 & 10,3 & 0,37 \\
\hline Segurar & 14,7 & Posicionar & 14,7 & 14,7 & 0,53 \\
\hline Segurar & 2 & Montar & 2 & 2 & 0,07 \\
\hline Segurar & 2 & Soltar & 2 & 2 & 0,07 \\
\hline
\end{tabular}

Fonte: Pesquisa de campo (2012)

Tabela 10 - Posto 9

\begin{tabular}{|c|c|c|c|c|c|}
\hline \multicolumn{2}{|c|}{ Mão esquerda } & \multicolumn{2}{|c|}{ Mão direita } & \multirow[b]{2}{*}{$\begin{array}{c}\text { Tempo Maior } \\
\text { (TMU) }\end{array}$} & \multirow[b]{2}{*}{ Tempo (s) } \\
\hline Micromovimento & $\begin{array}{l}\text { Tempo } \\
\text { (TMU) }\end{array}$ & Micromovimento & $\begin{array}{l}\text { Tempo } \\
\text { (TMU) }\end{array}$ & & \\
\hline $\begin{array}{l}\text { Segurar novo } \\
\text { conjunto }\end{array}$ & 5,8 & Transporte Vazio & 5,8 & 5,8 & 0,21 \\
\hline Segurar & 21 & Selecionar parafuso & 21 & 21 & 0,76 \\
\hline Segurar & 2 & Agarrar & 2 & 2 & 0,07 \\
\hline Segurar & 2 & Segurar & 2 & 2 & 0,07 \\
\hline Segurar & 10,3 & $\begin{array}{l}\text { Transporte } \\
\text { Carregado }\end{array}$ & 10,3 & 10,3 & 0,37 \\
\hline Segurar & 5,8 & Pré-posicionar & 5,8 & 5,8 & 0,21 \\
\hline
\end{tabular}




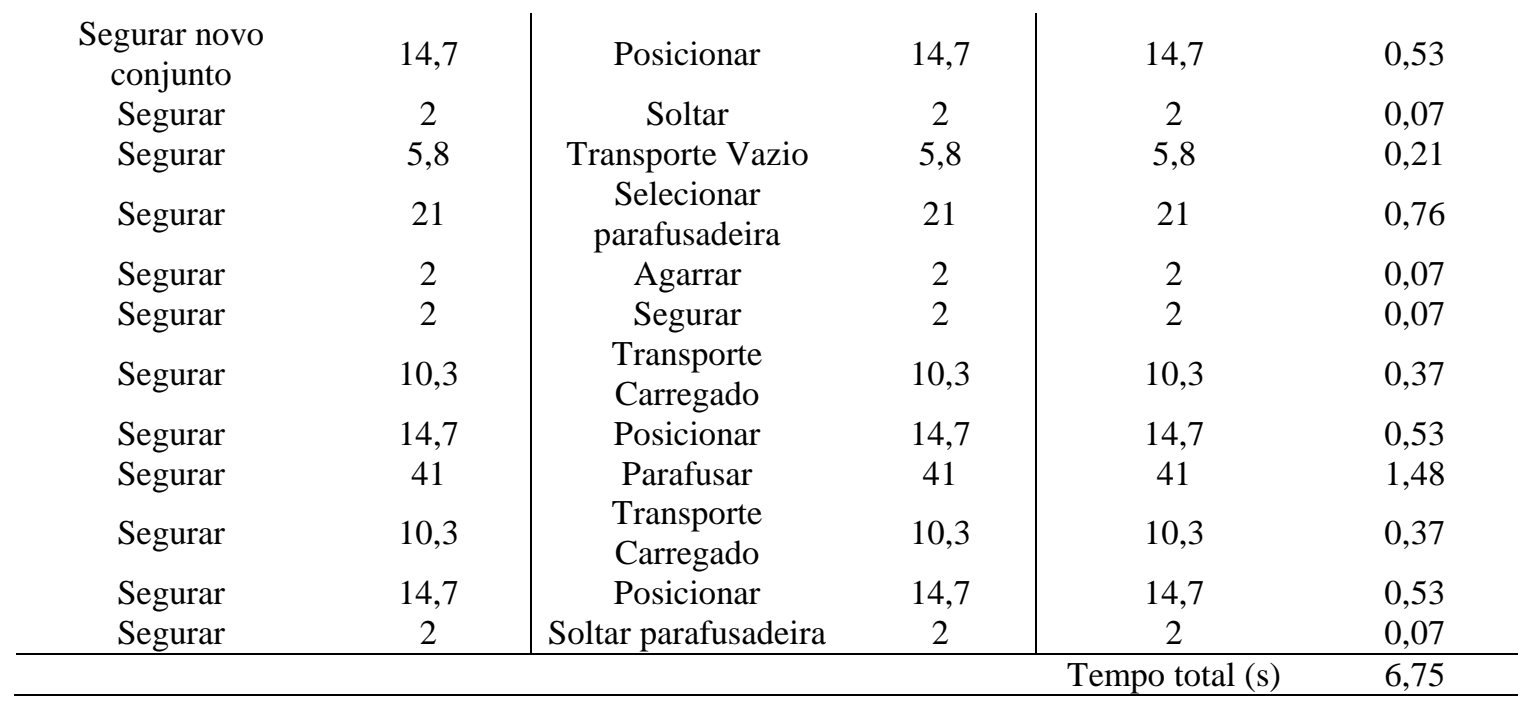

Fonte: Pesquisa de campo (2012)

Tabela 11 - Posto 10

\begin{tabular}{|c|c|c|c|c|c|}
\hline \multicolumn{2}{|c|}{ Mão esquerda } & \multicolumn{2}{|c|}{ Mão direita } & \multirow[b]{2}{*}{$\begin{array}{c}\text { Tempo Maior } \\
\text { (TMU) }\end{array}$} & \multirow[b]{2}{*}{ Tempo (s) } \\
\hline Micromovimento & $\begin{array}{l}\text { Tempo } \\
\text { (TMU) }\end{array}$ & Micromovimento & $\begin{array}{l}\text { Tempo } \\
\text { (TMU) }\end{array}$ & & \\
\hline $\begin{array}{l}\text { Segurar novo } \\
\text { conjunto }\end{array}$ & 5,8 & Transporte Vazio & 5,8 & 5,8 & 0,21 \\
\hline Segurar & 21 & Selecionar parafuso & 21 & 21 & 0,76 \\
\hline Segurar & 2 & Agarrar & 2 & 2 & 0,07 \\
\hline Segurar & 2 & Segurar & 2 & 2 & 0,07 \\
\hline Segurar & 10,3 & $\begin{array}{l}\text { Transporte } \\
\text { Carregado }\end{array}$ & 10,3 & 10,3 & 0,37 \\
\hline Segurar & 5,8 & Pré-posicionar & 5,8 & 5,8 & 0,21 \\
\hline $\begin{array}{l}\text { Segurar novo } \\
\text { conjunto }\end{array}$ & 14,7 & Posicionar & 14,7 & 14,7 & 0,53 \\
\hline Segurar & 2 & Soltar & 2 & 2 & 0,07 \\
\hline Segurar & 5,8 & Transporte Vazio & 5,8 & 5,8 & 0,21 \\
\hline Segurar & 21 & $\begin{array}{c}\text { Selecionar } \\
\text { parafusadeira }\end{array}$ & 21 & 21 & 0,76 \\
\hline Segurar & 2 & Agarrar & 2 & 2 & 0,07 \\
\hline Segurar & 2 & Segurar & 2 & 2 & 0,07 \\
\hline Segurar & 10,3 & $\begin{array}{l}\text { Transporte } \\
\text { Carregado }\end{array}$ & 10,3 & 10,3 & 0,37 \\
\hline Segurar & 14,7 & Posicionar & 14,7 & 14,7 & 0,53 \\
\hline Segurar & 41 & Parafusar & 41 & 41 & 1,48 \\
\hline Segurar & 10,3 & $\begin{array}{l}\text { Transporte } \\
\text { Carregado }\end{array}$ & 10,3 & 10,3 & 0,37 \\
\hline Segurar & 14,7 & Posicionar & 14,7 & 14,7 & 0,53 \\
\hline Segurar & 2 & Soltar parafusadeira & 2 & 2 & 0,07 \\
\hline
\end{tabular}

Fonte: Pesquisa de campo (2012)

Tabela 12 - Posto 11

\begin{tabular}{cc|cc|cc}
\hline \multicolumn{2}{c}{ Mão esquerda } & \multicolumn{2}{c}{ Mão direita } \\
\hline Micromovimento & $\begin{array}{c}\text { Tempo } \\
\text { (TMU) }\end{array}$ & Micromovimento & $\begin{array}{c}\text { Tempo } \\
\text { (TMU) }\end{array}$ & $\begin{array}{c}\text { Tempo Maior } \\
\text { (TMU) }\end{array}$ & Tempo (s) \\
\hline Segurar & 5,8 & Transporte Vazio & 5,8 & 5,8 & 0,21 \\
Segurar & 21 & $\begin{array}{c}\text { Selecionar Suporte } \\
\text { inferior }\end{array}$ & 21 & 21 & 0,76 \\
Segurar & 2 & Agarrar & 2 & 2 & 0,07 \\
Segurar & 2 & Segurar & 2 & 2 & 0,07 \\
Segurar & 10,3 & Transporte Carregado & 10,3 & 10,3 & 0,37 \\
Segurar & 14,7 & Posicionar & 14,7 & 14,7 & 0,53 \\
Segurar & 2 & Montar & 2 & 2 & 0,07
\end{tabular}




\begin{tabular}{|c|c|c|c|c|c|}
\hline Segurar & 2 & Soltar & 2 & 2 & 0,07 \\
\hline $\begin{array}{l}\text { Segurar novo } \\
\text { conjunto }\end{array}$ & 5,8 & Transporte Vazio & 5,8 & 5,8 & 0,21 \\
\hline Segurar & 21 & Selecionar parafuso & 21 & 21 & 0,76 \\
\hline Segurar & 2 & Agarrar & 2 & 2 & 0,07 \\
\hline Segurar & 2 & Segurar & 2 & 2 & 0,07 \\
\hline Segurar & 10,3 & Transporte Carregado & 10,3 & 10,3 & 0,37 \\
\hline Segurar & 5,8 & Pré-posicionar & 5,8 & 5,8 & 0,21 \\
\hline $\begin{array}{l}\text { Segurar novo } \\
\text { conjunto }\end{array}$ & 14,7 & Posicionar & 14,7 & 14,7 & 0,53 \\
\hline Segurar & 2 & Soltar & 2 & 2 & 0,07 \\
\hline Segurar & 5,8 & Transporte Vazio & 5,8 & 5,8 & 0,21 \\
\hline Segurar & 21 & $\begin{array}{c}\text { Selecionar } \\
\text { parafusadeira }\end{array}$ & 21 & 21 & 0,76 \\
\hline Segurar & 2 & Agarrar & 2 & 2 & 0,07 \\
\hline Segurar & 2 & Segurar & 2 & 2 & 0,07 \\
\hline Segurar & 10,3 & Transporte Carregado & 10,3 & 10,3 & 0,37 \\
\hline Segurar & 14,7 & Posicionar & 14,7 & 14,7 & 0,53 \\
\hline Segurar & 41 & Parafusar & 41 & 41 & 1,48 \\
\hline Segurar & 10,3 & Transporte Carregado & 10,3 & 10,3 & 0,37 \\
\hline Segurar & 14,7 & Posicionar & 14,7 & 14,7 & 0,53 \\
\hline Segurar & 2 & Soltar parafusadeira & 2 & 2 & 0,07 \\
\hline \multicolumn{5}{|r|}{ Tempo total (s) } & 8,90 \\
\hline
\end{tabular}

Fonte: Pesquisa de campo (2012)

Tabela 13 - Posto 12

\begin{tabular}{|c|c|c|c|c|c|}
\hline \multicolumn{2}{|c|}{ Mão esquerda } & \multicolumn{2}{|l|}{ Mão direita } & \multirow[b]{2}{*}{$\begin{array}{l}\text { Tempo Maior } \\
\text { (TMU) }\end{array}$} & \multirow[b]{2}{*}{ Tempo (s) } \\
\hline Micromovimento & $\begin{array}{l}\text { Tempo } \\
\text { (TMU) }\end{array}$ & Micromovimento & $\begin{array}{l}\text { Tempo } \\
\text { (TMU) }\end{array}$ & & \\
\hline $\begin{array}{l}\text { Segurar novo } \\
\text { conjunto }\end{array}$ & 5,8 & Transporte Vazio & 5,8 & 5,8 & 0,21 \\
\hline Segurar & 21 & Selecionar parafuso & 21 & 21 & 0,76 \\
\hline Segurar & 2 & Agarrar & 2 & 2 & 0,07 \\
\hline Segurar & 2 & Segurar & 2 & 2 & 0,07 \\
\hline Segurar & 10,3 & Transporte Carregado & 10,3 & 10,3 & 0,37 \\
\hline Segurar & 5,8 & Pré-posicionar & 5,8 & 5,8 & 0,21 \\
\hline $\begin{array}{l}\text { Segurar novo } \\
\text { conjunto }\end{array}$ & 14,7 & Posicionar & 14,7 & 14,7 & 0,53 \\
\hline Segurar & 2 & Soltar & 2 & 2 & 0,07 \\
\hline Segurar & 5,8 & Transporte Vazio & 5,8 & 5,8 & 0,21 \\
\hline Segurar & 21 & Selecionar parafusadeira & 21 & 21 & 0,76 \\
\hline Segurar & 2 & Agarrar & 2 & 2 & 0,07 \\
\hline Segurar & 2 & Segurar & 2 & 2 & 0,07 \\
\hline Segurar & 10,3 & Transporte Carregado & 10,3 & 10,3 & 0,37 \\
\hline Segurar & 14,7 & Posicionar & 14,7 & 14,7 & 0,53 \\
\hline Segurar & 41 & Parafusar & 41 & 41 & 1,48 \\
\hline Demora inevitável & 5,8 & Transporte Vazio & 5,8 & 5,8 & 0,21 \\
\hline Demora inevitável & 21 & $\begin{array}{c}\text { Selecionar o relógio } \\
\text { montado }\end{array}$ & 21 & 21 & 0,76 \\
\hline Demora inevitável & 2 & Agarrar & 2 & 2 & 0,07 \\
\hline Demora inevitável & 2 & Segurar & 2 & 2 & 0,07 \\
\hline Demora inevitável & 10,3 & Transporte Carregado & 10,3 & 10,3 & 0,37 \\
\hline Demora inevitável & 14,7 & Posicionar & 14,7 & 14,7 & 0,53 \\
\hline Demora inevitável & 2 & Soltar & 2 & 2 & 0,07 \\
\hline & & & & Tempo total (s) & 7,86 \\
\hline
\end{tabular}

Fonte: Pesquisa de campo (2012)

Para a empresa 2, os métodos de produção foram otimizados. Foi levado em conta todas as operações realizadas na empresa 1, dessa forma empregou-se o sistema geral de solução de problemas, analisando-o, pesquisando as possíveis soluções. Os processos foram divididos em 
várias operações simples. Cada movimento da mão foi questionado buscando eliminar, combinar ou rearranjar o ordenamento da operação a fim de facilitar a tarefa. Os micromovimentos são apresentados nas Tabelas 14 até 21.

Tabela 14 - Posto1

\begin{tabular}{|c|c|c|c|c|c|}
\hline \multicolumn{2}{|l|}{ Mão esquerda } & \multicolumn{2}{|l|}{ Mão direita } & \multirow[b]{2}{*}{$\begin{array}{l}\text { Tempo Maior } \\
\text { (TMU) }\end{array}$} & \multirow[b]{2}{*}{$\begin{array}{c}\text { Tempo } \\
\text { (s) }\end{array}$} \\
\hline Micromovimento & $\begin{array}{l}\text { Tempo } \\
\text { (TMU) }\end{array}$ & Micromovimento & $\begin{array}{l}\text { Tempo } \\
\text { (TMU) }\end{array}$ & & \\
\hline Transporte Vazio & 5,8 & Transporte Vazio & 5,8 & 5,8 & 0,21 \\
\hline Selecionar Lente & 21 & Selecionar Carcaça & 21 & 21 & 0,76 \\
\hline Agarrar & 2 & Agarrar & 2 & 2 & 0,07 \\
\hline Segurar & 2 & Segurar & 2 & 2 & 0,07 \\
\hline Transporte Carregado & 10,3 & Transporte Carregado & 10,3 & 10,3 & 0,37 \\
\hline Pré-posicionar & 5,8 & Segurar & 5,8 & 5,8 & 0,21 \\
\hline Posicionar & 14,7 & Segurar & 14,7 & 14,7 & 0,53 \\
\hline Montar & 2 & Segurar & 2 & 2 & 0,07 \\
\hline Soltar & 2 & Segurar & 2 & 2 & 0,07 \\
\hline Demora inevitável & 10,3 & Transporte Carregado & 10,3 & 10,3 & 0,37 \\
\hline Demora inevitável & 2 & $\begin{array}{l}\text { Soltar na mesa lente }+ \\
\text { carcaça montados }\end{array}$ & 2 & 2 & 0,07 \\
\hline Transporte Vazio & 5,8 & Transporte Vazio & 5,8 & 5,8 & 0,21 \\
\hline Selecionar encaixe da placa & 21 & Selecionar placa & 21 & 21 & 0,76 \\
\hline Agarrar & 2 & Agarrar & 2 & 2 & 0,07 \\
\hline Segurar & 2 & Segurar & 2 & 2 & 0,07 \\
\hline Transporte Carregado & 10,3 & Transporte Carregado & 10,3 & 10,3 & 0,37 \\
\hline Pré-posicionar & 5,8 & Segurar & 2 & 2 & 0,07 \\
\hline Posicionar & 14,7 & demora inevitável & 14,7 & 14,7 & 0,53 \\
\hline Transporte Carregado & 10,3 & Transporte Carregado & 10,3 & 10,3 & 0,37 \\
\hline Posicionar na mesa & 14,7 & Posicionar na mesa & 14,7 & 14,7 & 0,53 \\
\hline $\begin{array}{c}\text { Soltar na mesa placa }+ \text { encaixe da } \\
\text { placa }\end{array}$ & 2 & Soltar & 2 & 2 & 0,07 \\
\hline & & & & Tempo total (s) & 5,86 \\
\hline
\end{tabular}

Fonte: Pesquisa de campo (2012)

Tabela 15 - Posto 2

\begin{tabular}{|c|c|c|c|c|c|}
\hline \multicolumn{2}{|c|}{ Mão esquerda } & \multicolumn{2}{|c|}{ Mão direita } & \multirow[b]{2}{*}{$\begin{array}{l}\text { Tempo Maior } \\
\text { (TMU) }\end{array}$} & \multirow[b]{2}{*}{ Tempo (s) } \\
\hline Micromovimento & $\begin{array}{l}\text { Tempo } \\
\text { (TMU) }\end{array}$ & Micromovimento & $\begin{array}{l}\text { Tempo } \\
\text { (TMU) }\end{array}$ & & \\
\hline Transporte Vazio & 5,8 & Transporte Vazio & 5,8 & 5,8 & 0,21 \\
\hline $\begin{array}{l}\text { Selecionar } \\
\text { parafuso }\end{array}$ & 21 & $\begin{array}{c}\text { Selecionar } \\
\text { parafusadeira }\end{array}$ & 21 & 21 & 0,76 \\
\hline Agarrar & 2 & Agarrar & 2 & 2 & 0,07 \\
\hline Segurar & 2 & Segurar & 2 & 2 & 0,07 \\
\hline $\begin{array}{l}\text { Transporte } \\
\text { Carregado }\end{array}$ & 10,3 & $\begin{array}{l}\text { Transporte } \\
\text { Carregado }\end{array}$ & 10,3 & 10,3 & 0,37 \\
\hline Pré-posicionar & 5,8 & Pré-posicionar & 5,8 & 5,8 & 0,21 \\
\hline Posicionar & 14,7 & Posicionar & 14,7 & 14,7 & 0,53 \\
\hline Segurar & 2 & Parafusar & 41 & 41 & 1,48 \\
\hline Soltar & 2 & $\begin{array}{l}\text { Transporte } \\
\text { Carregado }\end{array}$ & 10,3 & 10,3 & 0,37 \\
\hline $\begin{array}{l}\text { Demora } \\
\text { inevitável }\end{array}$ & 2 & Segurar & 2 & 2 & 0,07 \\
\hline Transporte Vazio & 5,8 & Demora inevitável & 5,8 & 5,8 & 0,21 \\
\hline $\begin{array}{c}\text { Selecionar } \\
\text { parafuso }\end{array}$ & 21 & Demora inevitável & 21 & 21 & 0,76 \\
\hline Agarrar & 2 & Demora inevitável & 2 & 2 & 0,07 \\
\hline Segurar & 2 & Demora inevitável & 2 & 2 & 0,07 \\
\hline $\begin{array}{l}\text { Transporte } \\
\text { Carregado }\end{array}$ & 10,3 & $\begin{array}{l}\text { Transporte } \\
\text { Carregado }\end{array}$ & 10,3 & 10,3 & 0,37 \\
\hline Pré-posicionar & 5,8 & Pré-posicionar & 5,8 & 5,8 & 0,21 \\
\hline
\end{tabular}




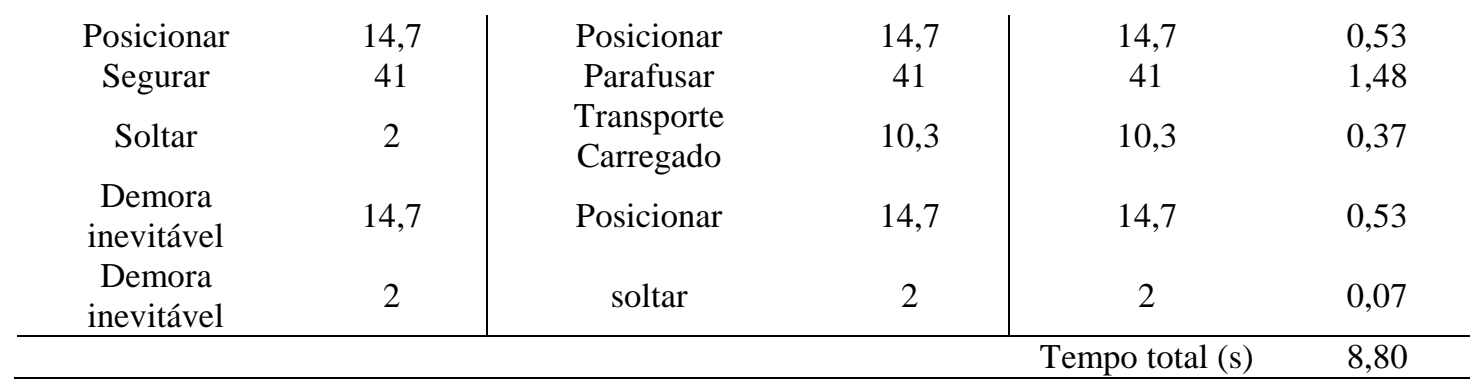

Fonte: Pesquisa de campo (2012)

Tabela 16 - Posto 3

\begin{tabular}{|c|c|c|c|c|c|}
\hline \multicolumn{2}{|c|}{ Mão esquerda } & \multicolumn{2}{|c|}{ Mão direita } & \multirow[b]{2}{*}{$\begin{array}{l}\text { Tempo Maior } \\
\text { (TMU) }\end{array}$} & \multirow[b]{2}{*}{ Tempo (s) } \\
\hline Micromovimento & $\begin{array}{l}\text { Tempo } \\
\text { (TMU) }\end{array}$ & Micromovimento & $\begin{array}{l}\text { Tempo } \\
\text { (TMU) }\end{array}$ & & \\
\hline Transporte Vazio & 5,8 & Demora inevitável & 5,8 & 5,8 & 0,21 \\
\hline $\begin{array}{c}\text { Selecionar } \\
\text { parafuso }\end{array}$ & 21 & Demora inevitável & 21 & 21 & 0,76 \\
\hline Agarrar & 2 & Demora inevitável & 2 & 2 & 0,07 \\
\hline Segurar & 2 & Demora inevitável & 2 & 2 & 0,07 \\
\hline $\begin{array}{l}\text { Transporte } \\
\text { Carregado }\end{array}$ & 10,3 & $\begin{array}{l}\text { Transporte } \\
\text { Carregado }\end{array}$ & 10,3 & 10,3 & 0,37 \\
\hline Pré-posicionar & 5,8 & Pré-posicionar & 5,8 & 5,8 & 0,21 \\
\hline Posicionar & 14,7 & Posicionar & 14,7 & 14,7 & 0,53 \\
\hline Segurar & 41 & Parafusar & 41 & 41 & 1,48 \\
\hline Soltar & 2 & $\begin{array}{l}\text { Transporte } \\
\text { Carregado }\end{array}$ & 10,3 & 10,3 & 0,37 \\
\hline $\begin{array}{c}\text { Demora } \\
\text { inevitável }\end{array}$ & 2 & Segurar & 2 & 2 & 0,07 \\
\hline Transporte Vazio & 5,8 & Demora inevitável & 5,8 & 5,8 & 0,21 \\
\hline $\begin{array}{l}\text { Selecionar } \\
\text { parafuso }\end{array}$ & 21 & Demora inevitável & 21 & 21 & 0,76 \\
\hline Agarrar & 2 & Demora inevitável & 2 & 2 & 0,07 \\
\hline Segurar & 2 & Demora inevitável & 2 & 2 & 0,07 \\
\hline $\begin{array}{l}\text { Transporte } \\
\text { Carregado }\end{array}$ & 10,3 & $\begin{array}{l}\text { Transporte } \\
\text { Carregado }\end{array}$ & 10,3 & 10,3 & 0,37 \\
\hline Pré-posicionar & 5,8 & Pré-posicionar & 5,8 & 5,8 & 0,21 \\
\hline Posicionar & 14,7 & Posicionar & 14,7 & 14,7 & 0,53 \\
\hline Segurar & 41 & Parafusar & 41 & 41 & 1,48 \\
\hline Soltar & 2 & $\begin{array}{l}\text { Transporte } \\
\text { Carregado }\end{array}$ & 10,3 & 10,3 & 0,37 \\
\hline $\begin{array}{l}\text { Demora } \\
\text { inevitável }\end{array}$ & 14,7 & Posicionar & 14,7 & 14,7 & 0,53 \\
\hline $\begin{array}{c}\text { Demora } \\
\text { inevitável }\end{array}$ & 2 & soltar & 2 & 2 & 0,07 \\
\hline & & & & Tempo total (s) & 8,80 \\
\hline
\end{tabular}

Fonte: Pesquisa de campo (2012)

Tabela 17 - Posto 4

\begin{tabular}{cc|cc|cc}
\hline \multicolumn{2}{c|}{ Mão esquerda } & \multicolumn{2}{|c}{ Mão direita } & Tempo \\
Micromovimento & $\begin{array}{c}\text { Tempo } \\
\text { (TMU) }\end{array}$ & Micromovimento & $\begin{array}{c}\text { Tempo Maior } \\
\text { (TMU) }\end{array}$ & Tempo (s) \\
\hline $\begin{array}{c}\text { Demora } \\
\text { inevitável }\end{array}$ & 5,8 & Transporte Vazio & 5,8 & 5,8 & 0,21 \\
Transporte Vazio & 5,8 & Selecionar peso 1 & 21 & 21 & 0,76 \\
Selecionar peso 1 & 21 & Agarrar & 2 & 2 & 0,07 \\
Agarrar & 2 & Segurar & 2 & 2 & 0,07
\end{tabular}




\begin{tabular}{|c|c|c|c|c|c|}
\hline Segurar & 10,3 & $\begin{array}{l}\text { Transporte } \\
\text { Carregado }\end{array}$ & 10,3 & 10,3 & 0,37 \\
\hline $\begin{array}{l}\text { Transporte } \\
\text { Carregado }\end{array}$ & 10,3 & Pré-posicionar & 5,8 & 5,8 & 0,21 \\
\hline Pré-posicionar & 5,8 & Posicionar & 14,7 & 14,7 & 0,53 \\
\hline Posicionar & 14,7 & Soltar & 2 & 2 & 0,07 \\
\hline Soltar & 2 & Demora inevitável & 2 & 2 & 0,07 \\
\hline Transporte Vazio & 5,8 & Transporte Vazio & 5,8 & 5,8 & 0,21 \\
\hline $\begin{array}{l}\text { Selecionar } \\
\text { parafuso }\end{array}$ & 21 & $\begin{array}{c}\text { Selecionar } \\
\text { parafusadeira }\end{array}$ & 21 & 21 & 0,76 \\
\hline Agarrar & 2 & Agarrar & 2 & 2 & 0,07 \\
\hline Segurar & 2 & Segurar & 2 & 2 & 0,07 \\
\hline $\begin{array}{l}\text { Transporte } \\
\text { Carregado }\end{array}$ & 10,3 & $\begin{array}{l}\text { Transporte } \\
\text { Carregado }\end{array}$ & 10,3 & 10,3 & 0,37 \\
\hline Pré-posicionar & 5,8 & Pré-posicionar & 5,8 & 5,8 & 0,21 \\
\hline Posicionar & 14,7 & Posicionar & 14,7 & 14,7 & 0,53 \\
\hline Segurar & 41 & Parafusar & 41 & 41 & 1,48 \\
\hline Soltar & 2 & $\begin{array}{l}\text { Transporte } \\
\text { Carregado }\end{array}$ & 10,3 & 10,3 & 0,37 \\
\hline $\begin{array}{c}\text { Demora } \\
\text { inevitável }\end{array}$ & 14,7 & Posicionar & 14,7 & 14,7 & 0,53 \\
\hline $\begin{array}{c}\text { Demora } \\
\text { inevitável }\end{array}$ & 2 & Soltar parafusadeira & 2 & 2 & 0,07 \\
\hline
\end{tabular}

Fonte: Pesquisa de campo (2012)

Tabela 18 - Posto 5

\begin{tabular}{cc|cc|cc}
\hline \multicolumn{2}{c|}{ Mão esquerda } & Mão direita & & \\
\hline Micromovimento & $\begin{array}{c}\text { Tempo } \\
\text { (TMU) }\end{array}$ & Micromovimento & $\begin{array}{c}\text { Tempo } \\
\text { (TMU) }\end{array}$ & $\begin{array}{c}\text { Tempo Maior } \\
\text { (TMU) }\end{array}$ & Tempo (s) \\
\hline Transporte Vazio & 5,8 & Transporte Vazio & 5,8 & 5,8 & 0,21 \\
Selecionar carcaça + & 21 & Selecionar placa + o conjunto & 21 & 21 & 0,76 \\
lente & montado & 2 & 2 & 0,07 \\
Agarrar & 2 & Agarrar & 2 & 0,07 \\
Segurar & 2 & Segurar & 10,3 & 10,3 & 0,37 \\
Transporte & 10,3 & Transporte Carregado & 14,7 & 14,7 & 0,53 \\
Carregado & 14,7 & Posicionar & 2 & 0,07 \\
Posicionar & 2 & Montar & 5,8 & 0,21 \\
Soltar na mesa & 5,8 & Transporte Vazio & 21 & 0,76 \\
Transporte Vazio & 21 & Selecionar Encaixe da carcaça & 21 & 0,07 \\
Selecionar Suporte & 2 & Agarrar & 2 & 2 & 0,07 \\
inferior & 2 & Segurar & 2 & 2 & 0,37 \\
Agarrar & 10,3 & Transporte Carregado & 10,3 & 10,3 & 0,53 \\
Segurar & Posicionar & 14,7 & 14,7 & 0,07 \\
Transporte & Montar & 2 & 2 & 0,07 \\
Carregado & Soltar & 5,8 & 5,8 & 0,21 \\
Posicionar & 14,7 & Transporte Vazio & & 2 &
\end{tabular}




\begin{tabular}{cc|cc|cc} 
Selecionar parafuso & 21 & Selecionar parafusadeira & 21 & 21 & 0,76 \\
Agarrar & 2 & Agarrar & 2 & 2 & 0,07 \\
Segurar & 2 & Segurar & 2 & 2 & 0,07 \\
Transporte & 10,3 & Transporte Carregado & 10,3 & 10,3 & 0,37 \\
Carregado & 5,8 & Posicionar & 14,7 & 14,7 & 0,53 \\
Pré-posicionar & Parafusar & & 41 & 1,476 \\
Posicionar & & Segurar & 2 & 2 & 0,072 \\
Soltar & 2 & & Tempo total (s) & 7,79 \\
\hline
\end{tabular}

Fonte: Pesquisa de campo (2012)

Tabela 19 - Posto 6

\begin{tabular}{|c|c|c|c|c|c|}
\hline \multicolumn{2}{|c|}{ Mão esquerda } & \multicolumn{2}{|c|}{ Mão direita } & \multirow[b]{2}{*}{$\begin{array}{l}\text { Tempo Maior } \\
\text { (TMU) }\end{array}$} & \multirow[b]{2}{*}{ Tempo (s) } \\
\hline Micromovimento & $\begin{array}{l}\text { Tempo } \\
\text { (TMU) }\end{array}$ & Micromovimento & $\begin{array}{l}\text { Tempo } \\
\text { (TMU) }\end{array}$ & & \\
\hline Transporte Vazio & 5,8 & Demora inevitável & 5,8 & 5,8 & 0,21 \\
\hline $\begin{array}{c}\text { Selecionar } \\
\text { parafuso }\end{array}$ & 21 & Demora inevitável & 21 & 21 & 0,76 \\
\hline Agarrar & 2 & Demora inevitável & 2 & 2 & 0,07 \\
\hline Segurar & 2 & Demora inevitável & 2 & 2 & 0,07 \\
\hline $\begin{array}{l}\text { Transporte } \\
\text { Carregado }\end{array}$ & 10,3 & $\begin{array}{l}\text { Transporte } \\
\text { Carregado }\end{array}$ & 10,3 & 10,3 & 0,37 \\
\hline Pré-posicionar & 5,8 & Posicionar & 14,7 & 14,7 & 0,53 \\
\hline Posicionar & 14,7 & Parafusar & 41 & 41 & 1,48 \\
\hline Soltar & 2 & Demora inevitável & 2 & 2 & 0,07 \\
\hline Transporte Vazio & 5,8 & Demora inevitável & 5,8 & 5,8 & 0,21 \\
\hline $\begin{array}{c}\text { Selecionar } \\
\text { parafuso }\end{array}$ & 21 & Demora inevitável & 21 & 21 & 0,76 \\
\hline Agarrar & 2 & Demora inevitável & 2 & 2 & 0,07 \\
\hline Segurar & 2 & Demora inevitável & 2 & 2 & 0,07 \\
\hline $\begin{array}{l}\text { Transporte } \\
\text { Carregado }\end{array}$ & 10,3 & $\begin{array}{l}\text { Transporte } \\
\text { Carregado }\end{array}$ & 10,3 & 10,3 & 0,37 \\
\hline Pré-posicionar & 5,8 & Posicionar & 14,7 & 14,7 & 0,53 \\
\hline Posicionar & 14,7 & Parafusar & 41 & 41 & 1,48 \\
\hline Soltar & 2 & Demora inevitável & 2 & 2 & 0,07 \\
\hline & & & & Tempo total (s) & 7,11 \\
\hline
\end{tabular}

Fonte: Pesquisa de campo (2012)

Tabela 20 - Posto 7

\begin{tabular}{|c|c|c|c|c|c|}
\hline \multicolumn{2}{|c|}{ Mão esquerda } & \multicolumn{2}{|c|}{ Mão direita } & \multirow[b]{2}{*}{$\begin{array}{c}\text { Tempo Maior } \\
\text { (TMU) }\end{array}$} & \multirow[b]{2}{*}{ Tempo (s) } \\
\hline Micromovimento & $\begin{array}{l}\text { Tempo } \\
\text { (TMU) }\end{array}$ & Micromovimento & $\begin{array}{l}\text { Tempo } \\
\text { (TMU) }\end{array}$ & & \\
\hline Transporte Vazio & 5,8 & Transporte Vazio & 5,8 & 5,8 & 0,21 \\
\hline $\begin{array}{l}\text { Selecionar } \\
\text { parafuso }\end{array}$ & 21 & $\begin{array}{c}\text { Selecionar Suporte } \\
\text { inferior }\end{array}$ & 21 & 21 & 0,76 \\
\hline Agarrar & 2 & Agarrar & 2 & 2 & 0,07 \\
\hline Segurar & 2 & Segurar & 2 & 2 & 0,07 \\
\hline $\begin{array}{l}\text { Demora } \\
\text { inevitável }\end{array}$ & 10,3 & Transporte Carregado & 10,3 & 10,3 & 0,37 \\
\hline $\begin{array}{l}\text { Demora } \\
\text { inevitável }\end{array}$ & 14,7 & Posicionar & 14,7 & 14,7 & 0,53 \\
\hline $\begin{array}{l}\text { Demora } \\
\text { inevitável }\end{array}$ & 2 & Montar & 2 & 2 & 0,07 \\
\hline Pré-posicionar & 5,8 & Soltar & 2 & 5,8 & 0,21 \\
\hline Posicionar & 14,7 & Demora inevitável & 14,7 & 14,7 & 0,53 \\
\hline Soltar & 2 & Demora inevitável & 2 & 2 & 0,07 \\
\hline $\begin{array}{l}\text { Demora } \\
\text { inevitável }\end{array}$ & & Transporte Vazio & 5,8 & 5,8 & 0,21 \\
\hline Transporte Vazio & 5,8 & $\begin{array}{c}\text { Selecionar } \\
\text { parafusadeira }\end{array}$ & 21 & 21 & 0,76 \\
\hline Selecionar & 21 & Agarrar & 2 & 2 & 0,07 \\
\hline
\end{tabular}




\begin{tabular}{|c|c|c|c|c|c|}
\hline \multicolumn{6}{|l|}{ parafuso } \\
\hline Agarrar & 2 & Segurar & 2 & 2 & 0,07 \\
\hline Segurar & 10,3 & Transporte Carregado & 10,3 & 10,3 & 0,37 \\
\hline $\begin{array}{l}\text { Transporte } \\
\text { Carregado }\end{array}$ & 10,3 & Posicionar & 14,7 & 14,7 & 0,53 \\
\hline Pré-posicionar & 5,8 & Parafusar & 41 & 41 & 1,48 \\
\hline Posicionar & 14,7 & Segurar & 14,7 & 14,7 & 0,53 \\
\hline Soltar & 2 & Demora inevitável & 2 & 2 & 0,07 \\
\hline & & & & Tempo total (s) & 6,98 \\
\hline
\end{tabular}

Tabela 21 - Posto 8

\begin{tabular}{|c|c|c|c|c|c|}
\hline \multicolumn{2}{|c|}{ Mão esquerda } & \multicolumn{2}{|c|}{ Mão direita } & \multirow[b]{2}{*}{$\begin{array}{l}\text { Tempo Maior } \\
\text { (TMU) }\end{array}$} & \multirow[b]{2}{*}{ Tempo (s) } \\
\hline Micromovimento & $\begin{array}{l}\text { Tempo } \\
\text { (TMU) }\end{array}$ & Micromovimento & $\begin{array}{l}\text { Tempo } \\
\text { (TMU) }\end{array}$ & & \\
\hline Transporte Vazio & 5,8 & Demora inevitável & 5,8 & 5,8 & 0,21 \\
\hline $\begin{array}{c}\text { Selecionar } \\
\text { parafuso }\end{array}$ & 21 & Demora inevitável & 21 & 21 & 0,76 \\
\hline Agarrar & 2 & Demora inevitável & 2 & 2 & 0,07 \\
\hline Segurar & 2 & Demora inevitável & 2 & 2 & 0,07 \\
\hline $\begin{array}{l}\text { Transporte } \\
\text { Carregado }\end{array}$ & 10,3 & Transporte Carregado & 10,3 & 10,3 & 0,37 \\
\hline Pré-posicionar & 5,8 & Posicionar & 14,7 & 14,7 & 0,53 \\
\hline Posicionar & 14,7 & Parafusar & 41 & 41 & 1,48 \\
\hline Soltar & 2 & Segurar & 2 & 2 & 0,07 \\
\hline $\begin{array}{l}\text { Demora } \\
\text { inevitável }\end{array}$ & 5,8 & Transporte Vazio & 5,8 & 5,8 & 0,21 \\
\hline $\begin{array}{l}\text { Demora } \\
\text { inevitável }\end{array}$ & 21 & $\begin{array}{c}\text { Selecionar o relógio } \\
\text { montado }\end{array}$ & 21 & 21 & 0,76 \\
\hline $\begin{array}{l}\text { Demora } \\
\text { inevitável }\end{array}$ & 2 & Agarrar & 2 & 2 & 0,07 \\
\hline $\begin{array}{l}\text { Demora } \\
\text { inevitável }\end{array}$ & 2 & Segurar & 2 & 2 & 0,07 \\
\hline $\begin{array}{l}\text { Demora } \\
\text { inevitável }\end{array}$ & 10,3 & Transporte Carregado & 10,3 & 10,3 & 0,37 \\
\hline $\begin{array}{l}\text { Demora } \\
\text { inevitável }\end{array}$ & 14,7 & Posicionar & 14,7 & 14,7 & 0,53 \\
\hline $\begin{array}{c}\text { Demora } \\
\text { inevitável }\end{array}$ & 2 & Soltar & 2 & 2 & 0,07 \\
\hline & & & & Tempo total (s) & 5,64 \\
\hline
\end{tabular}

Fonte: Pesquisa de campo (2012)

O estudo de tempos e movimentos determinou quanto tempo um operário qualificado gastou para executar alguma tarefa, este tempo é o tempo padrão, este tempo é usado para o planejamento da produção e estimar o custo da mão de obra. A ferramenta básica utilizada foi o sistema MTM de tempos sintéticos desenvolvidos.

Com os métodos desenvolvidos em cada posto de trabalho para cada empresa, pode-se determinar o tempo total, o tempo normal e o tempo padrão, assim, para melhor visualização dos resultados, estes foram dispostos nas Tabelas 22 e 23. 
Tabela 22 - Tempo padrão de cada posto da empresa 1

\begin{tabular}{c|c|c|c|c}
\hline Posto & $\begin{array}{c}\text { Tempo } \\
\text { Total(s) }\end{array}$ & $\begin{array}{c}\text { Tempo } \\
\text { Normal(s) }\end{array}$ & $\begin{array}{c}\text { Tempo } \\
\text { Padrão(s) }\end{array}$ & $\begin{array}{c}\text { Perda de } \\
\text { Balanceamento(\%) }\end{array}$ \\
\hline 1 & 5,99 & 6,17 & 6,24 & $32,52 \%$ \\
2 & 4,67 & 4,81 & 4,85 & $47,47 \%$ \\
3 & 4,67 & 4,81 & 4,85 & $47,47 \%$ \\
4 & 4,67 & 4,81 & 4,85 & $47,47 \%$ \\
5 & 6,67 & 6,87 & 6,94 & $24,86 \%$ \\
6 & 4,58 & 4,72 & 4,76 & $48,44 \%$ \\
7 & 4,67 & 4,81 & 4,85 & $47,47 \%$ \\
8 & 7,87 & 8,10 & 8,18 & $11,44 \%$ \\
9 & 6,75 & 6,95 & 7,02 & $24,04 \%$ \\
10 & 6,75 & 6,95 & 7,02 & $24,04 \%$ \\
11 & 8,90 & 9,17 & 9,26 & $-0,19 \%$ \\
12 & 7,86 & 8,09 & 8,17 & $11,56 \%$ \\
\hline Total & 74,02 &, 24 & 77,7601 & \\
\hline
\end{tabular}

Fonte: Pesquisa de campo (2012)

Tabela 23 - Tempo padrão de cada posto da empresa 2

\begin{tabular}{c|c|c|c|c}
\multicolumn{5}{c}{ Tabela 23 - Tempo padrão de cada posto da empresa 2 } \\
\hline Posto & $\begin{array}{c}\text { Tempo } \\
\text { Total(s) }\end{array}$ & $\begin{array}{c}\text { Tempo } \\
\text { Normal(s) }\end{array}$ & $\begin{array}{c}\text { Tempo } \\
\text { Padrão(s) }\end{array}$ & $\begin{array}{c}\text { Perda de } \\
\text { Balanceamento(\%) }\end{array}$ \\
\hline 1 & 5,86 & 6,03 & 6,09 & $34,06 \%$ \\
2 & 8,80 & 9,07 & 9,16 & $0,90 \%$ \\
3 & 8,80 & 9,07 & 9,16 & $0,90 \%$ \\
4 & 7,03 & 7,24 & 7,31 & $20,88 \%$ \\
5 & 7,79 & 8,02 & 8,10 & $12,29 \%$ \\
6 & 7,11 & 7,33 & 7,40 & $19,91 \%$ \\
7 & 6,98 & 7,19 & 7,26 & $21,45 \%$ \\
8 & 5,64 & 5,81 & 5,86 & $36,53 \%$ \\
\hline Total & 58,01 & 59,75 & 60,34 & \\
\hline
\end{tabular}

Fonte: Pesquisa de campo (2012)

As Tabelas 22 e 23 mostram que a Empresa 1 gasta 77,01s para produção de um produto, já a Empresa 2, 60,34s. Com a redução do tempo de produção, a empresa 2, para atender a demanda, subdividiu as tarefas em apenas oito postos de trabalho, diferentemente da empresa um que subdividiu em 12 postos de trabalho. Para que subdivisão das tarefas em postos de trabalho seja perfeito, a perda de balanceamento deverá ser zero, pois ela é o desvio do tempo de produção do posto em relação ao tempo necessário para a produção de um produto, que é o tempo imposto pelo mercado, no caso, ela é 9,24s. Assim quanto maior é a perda de balanceamento, maior é o tempo ocioso no posto de trabalho acarretando em um custo maior no produto. Comparando-se os postos de trabalho das duas empresas, nota-se que a empresa 1 possui perdas de balanceamentos maiores que os da empresa 2. Isto significa esta realizou alocação de recursos de modo eficiente, porém não perfeitas, pois como cada posto é responsável por um conjunto de micromovimentos, muitas vezes, elas não podem serem subdivididas. Outro ponto essencial, é que na empresa 1 no posto 11, a perda de balanceamento teve um valor negativo, ou seja, o tempo para a realização das tarefas neste posto ultrapassa o valor de 9,24s imposto pelo mercado, assim, ela não irá conseguir atender a demanda.

Portanto, verifica-se que a empresa 2 utilizou de modo eficiente as ferramentas básicas de gestão em relação a empresa 1, reduzindo dessa maneira, os custos que envolveria na produção. 


\title{
7. Conclusão
}

Comprova-se neste trabalho que os estudos e teorias evidenciados pelos autores e estudiosos no assunto de Tempos e Métodos, Estudo de Movimentos e a utilização de forma correta dessas ferramentas na organização reflete em grandes retornos e benefícios, em melhoria de eficiência produtiva e balanceamento da linha de produção. As ferramentas de gestão numa linha de produção é essencial para uma empresa manter-se competitivo. Um uso eficiente dessas ferramentas acarreta em uma diminuição dos custos de produção. Isto é um fator primordial no ambiente do mercado competitivo onde ganhos em tempo de produção ou eliminação de operações representam um diferencial competitivo com retornos financeiros consideráveis a longo prazo. Assim, para que a empresa se destaque no mercado e se diferencie das outras é fundamental que haja investimento no setor produtivo (FLUENTES, DIAZ, 2012).

Os ganhos da empresa 2 foram consideráveis, pois ela possui 4 colaboradores a menos, produz uma unidade com 16,67 s de diferença sem perder a produtividade do processo e o tempo de espera é menor pois as perdas de balanceamento de cada posto de trabalho foram relativamente menores, ou seja, foi reduzido o tempo ocioso. Este ganho para a organização só foi possível após o trabalho de análise dos tempos e movimentos.

\begin{abstract}
In this work we intend to apply the concepts from literature regarding time and motion studies in order to evaluate a case study comparing its productivity when using appropriate techniques, based on the literature review on the topic. The objective is to analyze the techniques applied in the area aiming at providing enhanced operational efficiency, optimization procedures and performing the balancing of the production line creating a division and a subdivision of all the movements necessary for execution of each task in an ordinated series of simple movements that also eliminate useless moves. The theories and techniques from the study of time and motion, general processes of problem solving, work study, method development, ergonomics and micromotion study are essential elements for analyzing manufacturing productivity. These studies rationalize work and can eliminate major problems found in any company where there is mass production on a large scale and with high volume of employees distributed throughout the production process.
\end{abstract}

Key-words: times; methods; competitiveness.

\section{Referências}

ABRAHÃO, J.; SZNELWAR, L. I.; SILVINO, A.; SARMET, M.; PINHO, D. Introdução à ergonomia da prática à teoria. São Paulo: Blücher, 2009.

BARNES, R. M. Estudo de movimentos e de tempos: projeto e medida do trabalho, 6.ed. São Paulo, Edgard Blücher, 1977.

BOLIS, I. Contribuição da ergonomia para melhoria do trabalho e para o processo de emancipação dos sujeitos., São Paulo: USP, 2011. Dissertação de mestrado do programa de pós-graduação em Engenharia de Produção, Escola Politécnica, Universidade de São Paulo, 2011. 
CHAYET, S.; KOUVELIS, P.; YU D. Z. Product variety and capacity investments in congested production systems. Manufacturing \& Service Operations Management, v.13, n. 3, pp. 390-403, Summer, 2011. cross ref

DAILY, B. F.; BISHOP J. W.; MASSOUD J. A. The role of training and empowerment in environmental performance: A study of the Mexican maquiladora industry. International Journal of Operations \& Production Management, $v$. 32 , pp. $631-647,2012$. crossref

DANIELlOU, F. A ergonomia em busca de seus princípios: debates epistemológicos. São Paulo, Edgar Blücher, 2004.

ERNEST J. M., Human Enginnering. McGraw-Hill Book. Co. New York,1957.

FALZON, P. Ergonomia. São Paulo, Edgard Blücher, 2007.

FLUENTES J. M.; DIAZ M. S. Learning on lean: a review of thinking and research. International Journal of Operations \& Production Management, v. 32 n. 5, 2012.

FURLAN, A.; VINELLI, A.; PONT, G. D. Complementarity and lean manufacturing bundles: an empirical analysis. International Journal of Operations \& Production Management, v. 3, pp. 835 - 850, 2011. crossref

GUPTA, M.; BOYD, L. An excel-based dice game: an integrative learning activity. International Journal of Operations \& Production Management, v. 31 n. 6, 2011. crossref

HASLE P.; BOJESEN, A.; JENSEN, P. L.; BRAMMING, P. Lean and the working environment: a review of the literature. International Journal of Operations \& Production Management, v. 32 n. 7, pp. 829-849, 2012. crossref

IIDA. I. Ergonomia: projeto e produção. São Paulo, Edgard Blücher, 2a ed., 2005.

JIMÉNEZ-JIMÉNEZ, D.; COSTA M. M. The performance effect of hrm and tqm: a study in Spanish organizations. International Journal of Operations \& Production Management, v.. 29, 12, pp.1266-1289, 2009. cross ref

JÚNIOR TUJ, A.; ROCHA, I. O.; SABÁ, R. F. B. Realização de estudo de tempos e movimentos numa indústria de colchões. XXII Encontro Nacional de Engenharia de Produção, Curitiba-Paraná, 23-25 de outubro, 2002.

MOREIRA, D. A. Administração da Produção e Operações. São Paulo: Pioneira Thompson Learning, 2002.

NARASIMHAN, R.; KULL, T. J.; NAHM, A. Alternative relationships among integrative beliefs, time-based manufacturing and performance. International Journal of Operations \& Production Management, v. 32, pp.496524, 2012. crossref

OPENSHAW, S. .Ergonomics and design - A reference guide. Allsteel Inc, 2004.

RIBEIRO, J. Organização de um sistema de produção em células de fabricação. Gestão e Produção, v. 9, n. 1, p. 6277, abril, 2002. crossref

SLACK, N. Administração da produção. $2^{a}$ ed. - São Paulo; Atlas, 2002.

STERNBERG H.; STEFANSSON G.; WESTERNBERG E.; GENNÄS R. B.; ALLENSTRÖM, E.; NAUSKA, M. L. Applying a lean approach to identify waste in motor carrier operations. International Journal of Productivity and Performance Management, v. 62, pp.47-65, 2013. crossref

\section{Dados dos autores}

Nome Completo: Delmo Alves de Moura

Filiação institucional: Universidade Federal do ABC

Curso de Engenharia de Gestão

Centro de Engenharia, Modelagem e Ciências Sociais Aplicadas - CECS 
Função: Professor Adjunto II

Endereço: Rua Santa Adélia, 166. CEP 09210-170 - Santo André - São Paulo - Brasil e-mail: delmo.moura@ufabc.edu.br

Nome Completo: Roberto Denin Liu

Filiação institucional: Universidade Federal do ABC

Curso de Engenharia de Gestão

Centro de Engenharia, Modelagem e Ciências Sociais Aplicadas - CECS

Função: Graduando do curso de Engenharia de Gestão

Endereço: Rua Santa Adélia, 166. CEP 09210-170 - Santo André - São Paulo - Brasil e-mail: liudenin@gmail.com

Submetido em: 05/07/2013

Aceito em: 15/10/2014 